\title{
Minimasi Biaya Distribusi Makanan Ringan pada UKM Marcuy dengan Metode Stepping Stone, Least Coast, VAM dan MODI
}

Rina Nurhidayati ${ }^{*}$, Ilham Falani ${ }^{2}$, Aditia Maulana Ahmad Ruchianto ${ }^{3}$, Muhamad Naufal ${ }^{4}$, Tania Nur Azizah ${ }^{5}$, Velyda Noer Praniasty ${ }^{6}$

Program Studi Teknik Industri, Universitas Indraprasta PGRI Jakarta ${ }^{1,2,3,4,5,6}$

rin4nurhidayati@gmail.com ${ }^{1}$, ,ilhamfalani@gmail.com ${ }^{2}$, maulanaaditia203@gmail.com $^{3}$, muhamadna $\underline{\text { ufal0511@gmail.com }}^{4}$, tanianur026@ gmail.com ${ }^{5}$,velydanp@gmail.com ${ }^{6}$

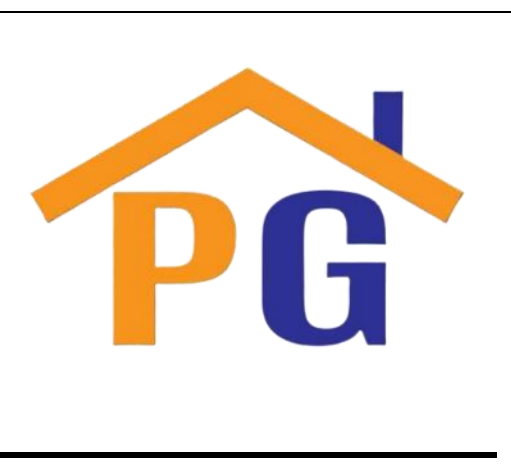

Riwayat Artikel

Diterima pada 15 Desember 2021

Revisi 1 pada 19 Desember 2021

Revisi 2 pada 23 Desember 2021

Revisi 3 pada 24 Januari 2022

Revisi 4 pada 3 Februari 2022

Revisi 5 pada 8 Februari 2022

Disetujui pada 8 Februari 2022

\begin{abstract}
Purpose: The purpose of this research is to minimization of snack distribution costs at Marcuy SMEs using the Stepping Stone, Least Coast, VAM and MODI Method.

Method: This study uses the type of data obtained is secondary data, namely the data obtained directly at UKM Makaroni Cihuy. In data processing, the data is processed using the transportation model, namely the method of Stepping Stone, least cost, vogel approximation, and modi.
\end{abstract}

Result: Based on the results of research on UKM Marcuy for ensure product delivery budget process using the Stepping Stone, Least Coast, Vogel Approximation Method (VAM), and Modified Distribution (MODI) methods. From the calculation using the four methods get the same result, namely the distribution costs incurred are Rp. 31.750,- for the type of product packaging 90 gr and Rp. 67.000 ,- for the type of product packaging $133 \mathrm{gr}$.

Limitation: This research is limited to the problem of minimizing the cost of distribution of snacks in UKM Marcuy. In addition, this study is also limited by the transportation methods used, including the Steppingstone, Least Cost, VAM, and MODI methods.

Contribution: This research is expected to provide an optimal solution to the problem of optimization of distribution costs in UKM Marcuy. Furthermore, this research can be a reference for research related to the implementation of the stepping stone, least cost, VAM, and MODI methods in minimizing distribution costs.

Keywords: Least Coast, Stepping Stone, Vogel Approximation, Modified Distribution

How to Cite: Nurhidayati, R., Falani, I., Ruchianto, A,M,A., Naufal, M., Azizah, T,A., Praniasty, V,N. (2021). Minimasi Biaya Distribusi Makanan Ringan pada UKM Marcuy dengan Metode Stepping Stone, Least Coast, VAM dan MODI. Studi Ilmu Manajemen dan Organisasi, 2(2), 167-181.

\section{Pendahuluan}

Aktivitas dalam mengirim barang memiliki keterkaitan yang utama dengan distribusi yakni penyampaian jasa atau barang yang berasal dari produsen ke konsumen agar melakukan pemenuhan keperluan manusia. Tiap orang perlu mengirim barang secara cepat dan memiliki keamanan agar dapat mempunyai kepastian kalau barang yang dalam pengiriman tiba di waktu dan tempat yang akurat. Dikarenakan keperluan mengirim barang sudah menjadi hal pokok tiap orang. Dalam upaya menjaga keberlangsungannya, sebuah perusahaan perlu mempertimbangkan pengoptimalan distribusi jasa atau barang kepada konsumen, karena hal ini merupakan bagian dari kualitas pelayanan yang dapat meningkatkan citra perusahaan seiring dengan meningkatnya kepuasan konsumen. (Kurniasih dan Elizabeth, 2021; Widyawati dan Faeni, 2021). 
Penerapan metode ilmiah untuk persoalan rumit untuk pembimbingan dan pemulihan pengaturan yang lapang dari bahan baku, mesin, bahan baku, anggaran dalam usaha, pemerintahan, pertahanan dan manusia merupakan riset operasi (Haobenu et al, 2021). Suatu cara yang dipakai untuk pengiriman produk dan jasa ke internal dan eksternal kota. Mengantarkan produk ke berberapa lokasi, sebagai bagian dari fungsional perusahaan, terutama ongkos transportasi yang diperlukan tidak sedikit. Oleh karena itu, dibutuhkan persiapan yang baik supaya ongkos transportasi yang dihasilkan memiliki daya guna yang baik, dan tidak menjadi masalah yang dapat mengeluarkan banyak biaya. Adanya jasa mengirim barang telah menjadi kepentingan bagi setiap orang atau instansi.

Secara umum permasalahan distribusi barang memiliki keterkaitan dengan memilih rute pada rantai distribusi suatu benda atau produk dari segenap sumber yang memiliki penawaran terbatas dan memiliki beberapa tujuan terhadap suatu permintaan dengan ongkos pengiriman seminimal mungkin. Dikarenakan hanya terdapat satu jenis barang atau produk, maka salah satu tempat tujuan bisa mencukupi permintaan yang memiliki asal dari satu atau beberapa sumber. Persepsi mendasar dari model ini ialah ongkos pengiriman suatu rute linier dengan kuantitas unit dalam pengiriman. Unit yang ada dalam proses pengiriman memiliki ketergantungan dengan beraneka produk dalam proses pangangkutan. Hal yang paling utama yaitu unit yang ditawarkan dan barang yang diminta akan diangkut harus secara konstan. Ketika memakai cara transportasi bagian tata laksana melakukan pencarian trayek peredaran untuk dapat memaksimalkan suatu destinasi. Apabila bertujuan meminimalkan jumlah ongkos pengiriman, maksimalkan penghasilan atau minimalkan waktu yang terpakai.

Pada cara ini, riset operasi memiliki keterkaitan dengan corak ialah riset operasi. Corak ialah korelasi atau keterkaitan elemen yang mendorong pengaturan. Corak pada riset operasi ialah cara optimasi, yaitu cara yang membongkar persoalan ilmu hitung dan mewujudkan balasan terbaik dan pencarian ketetapan atau akibat utama untuk masalah yang melengkapi keadaan spesifik secara tepat. Metode yang dipakai sebagai pengelolaan distribusi yang bersumber dari lokasi yang menyuplai produk yang sama ke lokasilokasi yang diperlukan dengan maksimal menggunakan ongkos yang paling murah ialah model transportasi.

Corak transportasi ialah suatu persoalan program linier secara lebih luas, di model transportasi terdapat pembahasan soal menentukan perencanaan ongkos terendah (lowest cost) untuk transportasi (pengangkutan) yang memiliki asal dari beberapa lokasi asal (starting location) misalkan ke beberapa destinasi tujuan (destinations). Secara esensi permasalahan transportasi ialah permasalahan program linier yang bisa terselesaikan menggunakan metode simpleks. Dikarenakan metode simpleks mengembangkan penyelesaian yang lebih rumit, oleh karena itu penyelesaian masalah transportasi dapat lebih sederhana apabila menggunakan Metode Stepping Stone, Metode biaya terendah (Least Coast) dan metode MODI (Modified Distribution).

Salah satu yang berperan penting pada pertumbuhan ekonomi dan pembangunan ekonomi nasional di Indonesia ialah dengan adanya usaha kecil dan menengah (UKM), selain itu UKM berperan untuk menyalurkan tenaga kerja, pemerataan pembangunan serta dapat menjadi roda penggerak pada pertumbuhan aktivitas ekonomi secara nasional. Konsentrasi perkembangan usaha tersebut mempunyai definisinya sendiri sebgagai usaha untuk menurunkan tingkat ketimpangan ekonomi pada negara. Perkembangan dan peningkatan bidang UKM terutama bagi beberapa negara dengan perolehan per kapita yang kecil dapat dimaknai seperti suatu tolak ukur kesuksesan pembangunan. (Primiana, 2009). Marcuy (Makaroni Cihuy) ialah suatu Usaha Mikro, Kecil, dan Menengah (UMKM) pada makanan ringan yaitu makaroni. Makaroni cihuy memiliki 4 varian rasa dalam kemasan 90 gr dan 133 gr. Sebagai produsen, agar produknya sampai ke tangan konsumen, marcuy melakukan distribusi produknya yang berasal dari 2 lokasi gudang di Pasar Minggu dan Setu Babakan ke 3 lokasi distributor yang berada di Depok, Pekayon dan Citereup sesuai dengan persediaan dan permintaan yang diterima.

\section{Tinjauan Pustaka}

Miro (2005), berkata bahwa transportasi ialah upaya memindahkan atau mengerakan yang memiliki asal dari suatu lokasi ke lokasi lainnya dengan memakai beberapa alat ekslusif. Transportasi dipakai 
agar membuat lebih mudah manusia ketika menjalankan kegiatan sehari-hari. Persmasalahan soal transportasi pada awalnya mempunyai formula yaitu suatu urutan khusus agar memperoleh strategi biaya yang rendah ketika peredaran elemen yang sama dari salah satu produk akan beberapa lokasi negosiasi (asal) menuju beberapa lokasi pengharapan (destinasi).

Salah satu opsi yang dipakai untuk menyelesaikan problematika transportasi, beberapa diantaranya yakni pendistribusian suatu barang berasal dari beberapa destinasi sebagai acual agar menurunkan biaya pengantaran yang terjadi ialah model transportasi.

Metode transportasi ialah problem menurunkan ongkos distribusi dengan memilih lokasi tujuan dari sumber ke tujuan untuk menurunkan ongkos transportasi barang. Metode transportasi ialah suatu cara yang dipakai agar bisa melerai problem transportasi, termasuk problem mendistribusikan barang atau produk dari beberapa destinasi (permintaan, destinasi), dengan destinasi menurunkan ongkos ransportasi pengantaran dikeluarkan.

Metode transportasi juga bisa dipakai agar dapat melakukan penyelesaian beberapa masalah soal optimasi. Masalah soal transportasi berkenaan dengan memilih rute (jalur) dalam mengangkut suatu barang atau produk yang memiliki akibat jumlah ongkos dari proses angkut minimal. Masalah soal pengangkutan yang kerap terjadi sehari-hari, memiliki suatu kelompok ekslusif masalah metode ini.

Permasalahan pengangkutan muncul apabila salah satu perusahaan melakukan percobaan agar dapat melakukan penentuan opsi dalam mengirimkan (distribusi) salah satu opsi barang atau produk (item) yang memiliki asal dari sejumlah sumber (lokasi dalam menawar) kepada beberapa tujuan (lokasi permintaan) yang bisa menimalisir ongkos. Target pada pemasalahan pengangkutan ialah melakukan pengalokasian produk yang tersedia pada asal seperti itu akhirnya bisa mencukupi seluruh keperluan di destinasi. Masalah yang biasa dihadapi kerap meningkatnya ongkos dalam memasarkan dikarenakan tidak ada keteraturan corak dalam melakukan distribusi yang memiliki asal dari suatu sumber tempat ke tempat tujuan dilakukan memasarkan, oleh karena itu perusahaan memiliki upaya agar dapat memaksimalkan ongkos pengiriman yang dianggarkan. Soal tersebut apabila diabaikan bisa menimbulkan akibat kemerosotan untuk perusahaan. Mengacu dari kejadian itulah pada penelitian ini melakukan pencarian agar dapat menemukan jalan keluar dengan memilih rute (jalur) ketika mengangkut atau mendistribusikan yang memiliki akibat biaya total dalam mengangkut atau mendistribusikan hal itu optimal. Ketika menentukan salah satu rute melakukan distribusi yang akurat dapat menggunakan metode transportasi pada program liniear.

Taha (1996) serta Pranati, Jaya, \& Sahari (2018) mengemukakan bahwa pemindahan serta pengiriman produk kepada konsumen, biaya pengiriman yang terbaik ialah salah satu kategori untuk mengkategorikan konsumen pada derajat kepuasan terbaik ketika pembelian atau pemakaian salah satu produk atau jasa. Sebagai upaya mengatasi hal tersebut, dicanangkan model transportasi yang akurat. Maksud dari corak transportasi yaitu sebagai upaya menetapkan bagian barang yang perlu diantarkan berawal berbagai tempat asal menuju berbagai destinasi, sehingga meminimalkan jumlah ongkos pengagkutan.

Pengimplementasian pada teknik transportasi agar mempercepat alur pada suatu pengiriman, dan bisa memaksimumkan biaya mengirim dari asal meunu tujuan, dan UMKM berfungsi agar meminimalisirkan biaya atau cost yang dikeluarkan untuk transportasi.

Menerapkan teknik transportasi yang baik serta tepat akan memudahkan proses distribusi, Mengoptimalkan pendistribusian dari tempat asal ke tujuan, serta membantu meminimalkan jumlah tarif transportasi. Dengan menggunakan teknik transportasi, tarif yang tidak perlu dapat dihilangkan, pendistribusian produk bisa dilakukan tanpa hambatan, kemampuan pelaku usaha akan meninkat, serta 
meminimalisir tenaga dan waktu dapat. Oleh karena itu, penerapan model transportasi untuk anggaran dapat menyelesaikan masalah barang dari sumber ke destinasi, didapatkan anggaran pengangkutan produk yang optimal. Masalah dalam pengiriman produk bisa saja terjadi. Sehubungan dengan hal tersebut, anggaran transportasi harus diatur supaya barang tetap terdistribusi dengan baik begitu juga dengan pengeluaran dan pemasukan.

Tujuan awal model transportasi ialah melakukan pemindahan produk atau barang yang berasal sejak suatu lokasi menuju lokasi berbeda menggunakan ongkos paling minimal sehingga tidak perlu repetisi akan proses mengangkut. Bersamaan aspek-aspeknya yaitu tiap permintaan tujuan konsumen dapat secara penuh dan asal lokasi tidak mungkin melakukan pengiriman barang lebih banyak dari daya tampung. Transportasi memiliki keseimbangan apabila total dilakukan pengiriman atau pengangkutan yang berasal ke salah satu destinasi dapat menyesuaikan akan total melakukan meminta atau daya tampung lokasi awal. Transportasi tak sejalan bila total sediaan yang memiliki asal dari beberapa lokasi asal tidak serupa bersama total permohonan sekian lokasi destinasi. Aminudin (2005) "Prinsip-Prinsip Riset Operasi" berkata jika permasalahan tentangl transportasi terkonsentrasi di melakukan pilihan rute pada rantai pengiriman produk melalui sentral industri dan pengiriman gudang atau penyambung pengiriman gudang domisili dan pengiriman penyisihan domisili. Entah itu permasalahan tentang transportasi ataupun permasalahan tentang bertugas ialah kepingan dari kerangka permasalahan tentang program linier khusus yang biasa disebut tentang rantai jaringan kerja. Permasalahan tentang transportasi awalnya diidentifikasikan untuk langkah khas agar mendapat ongkos terkecil ketika melakukan distribusi produk sama melalui produk akan beberapa lokasi negosiasi (asal) ke lokasi ajakan (destinasi).

Ongkos mengirim produk pula mempunyai keterkaitan dengan rentang sebar benda serta tipe benda yang dikirim perihal ini hendak mengakibatkan berapa banyak total ongkos yang hendak dianggarkan buat mengirim benda akan lokasi yan berlainan serta tipe benda yang berlainan juga.

Teknik Vogel Aproximation diekspektasikan sanggup menganggarkan bayaran mengirim benda terkecil, supaya bayaran yang ditentukan suatu industri jasa mengirim benda bisa berlomba akan perusahan jasa mengirim yang lain.

Tujuan dilakukan penelitian ini dikarenakan untuk meminimalkan anggaran pendistribusian produk pada UKM marcuy, pada penelitian ini memakai model transportasi dengan teknik Stepping Stone, Least Cost, Vogel Approximation Method (VAM) dan Modified Distribution (MODI) untuk menentukan ongkos mengirim paling minimal.

a. Metode Stepping Stone (Metode batu loncat)

Stepping Stone ialah sesuatu cara kesekian buat peralihan yang berasal sesuatu pemecahan dini yang layak ke pemecahan yang maksimal dalam tata cara transportasi.

Menurut Heizer dan Render (2001) yaitu pada metode Stepping Stone atau metode batu loncat menyokong untuk menyelesaikan kepada permasalahan yang optimal. Metode ini berfungsi untuk menguji coba kelancaran ongkos yang bermula akan pengangkutan barang yang dilewati lajur yang sudah ditetapkan dan tidak terdapat jalan keluar.

Sehabis pemecahan layak dasar dini diperoleh dari permasalahan transportasi, langkah selanjutnya merupakan memencet kebawah bayaran transportasi denngan mencantumkan variabel non basis (ialah pembagian benda ke kotak belum terisi) menuju pemecahan. Proses penilaian variabel yang membolehkan terbentuknya revisi pemecahan serta setelah itu mengalokasikan kembali dinamakan tata cara stepping stone.

Berikut persamaan secara Umum :

Fungsi tujuan: 


$$
\text { Minimum } Z=\sum_{j=1}^{m} \sum_{i=1}^{n} C_{i j} X_{i j}
$$

Dengan Batasan:

$\sum_{j=1}^{m} X_{i j}=A_{I} ; i=1,2, \ldots n$

$\sum_{i=1}^{m} X_{i j}=B_{I} ; j=1,2, \ldots n$

$\mathrm{Cij}=$ ongkos mengirim per benda dari asal $\mathrm{i}$ ke destinasi $\mathrm{j}$.

$\mathrm{Xij}=$ total benda yang dikirimkan dari asal $\mathrm{i}$ ke destinasi $\mathrm{j}$.

Ai. = kuantitas benda diusulkan atau daya tampung dari lokasi awal i.

$\mathrm{Bj}=$ kuantitas benda dibuatkan oleh destinasi $\mathrm{j}$.

$\mathrm{m}=$ kuantitas sumber.

$\mathrm{n}=$ kuantitas tujuan.

Menurut Heizer dan Render (2001), tahapan pengujian cara Stepping Stone yakni:

1) Sortir salah satu sel yang masih kosong untuk pengujian.

2) Di sel kosong, tarik garis berlawanan arah jarum jam, lalu kembali ke sel kosong melalui sel yang ditetapkan ke unit produk sesuai dengan rute transportasi, dan gunakan garis vertikal atau garis vertikal untuk menguji tingkat pergerakannya.

3) Pertama-tama kenakan fitur positif (+) sel yang kosong, lalu kenakan fitur negatif (-) ke sel berikutnya, lalu ulangi fitur positif (+) untuk sel berikutnya dan gunakan lagi fitur negatif (-) Fitur menghadap sel berikutnya. Selanjutnya bergantian hingga kembali ke sel semula yang masih kosong sebelumnya.

4) Hitung indeks perbaikan dengan menjumlahkan semua unit pembayaran di setiap sel dengan karakteristik positif, kemudian mengurangi semua unit pembayaran yang terdapat di setiap sel dengan karakteristik negatif.

5) Ulangi langkah 1 (satu) sampai 4 (empat) sampai diperoleh indeks perbaikan seluruh sel kosong. Pada hasil perhitungan keseluruhan indeks perbaikan, nilainya sama dengan nol atau lebih besar dari satu sampai tercapai derajat ketuntasan maksimal. Jika tidak, ada baiknya meminimalkan atau memaksimalkan jumlah pembayaran sebelum Anda perlu mengubah alokasi di sel yang sudah berisi alokasi rute pengiriman dari sumber pasokan.

Algoritma program batu loncatan dapat ditulis sebagai berikut:

1) Uji batu loncat adalah menghitung jumlah sel dasar pada pemecahan basa awal. Jika jumlah sel dasar kurang dari $m+n-1$, maka akan terjadi penurunan.

2) Gunakan persamaan $\mathrm{Ui}+\mathrm{Vj}=\mathrm{Cij}$ untuk menghitung nilai $\mathrm{Ui}$ dan $\mathrm{Vj}$ untuk semua primitif. Pastikan bahwa Ui atau Vj adalah nol sebelumnya.

3) Hitung nilai biaya penggantian setiap sel non-basis sebagai Dij, dengan menggunakan persamaan: $\mathrm{Dij}=\mathrm{Cij}-\mathrm{Ui}-\mathrm{Vi}$.

4) Jika semua harga Dij lebih besar atau sama dengan 0 sebelum solusi dimaksimalkan, jika kebalikannya harus dicoba, evaluasi ulang adalah memilih Xij dengan nilai Dij sangat negatif (nilai sangat negatif) sebagai input yang dapat diubah. Alokasi objek pada variabel masuk didasarkan pada pengaturan jalan tertutup.

5) Ulangi langkah (2) sampai dengan (4) hingga nilai Dij $\geq 0$.

\section{b. Least Cost}

Prosedur pemecahan dini perkara transportasi apabila memakai tata cara bayaran terkecil ataupun terendah merupakan alokasikan setinggi bisa jadi beberapa komoditas pada sel yang memiliki bayaran unit terkecil dalam totalitas tabel. Bila terdapat sebagian sel yang mempunyai bayaran unit terkecil yang sama hingga seleksi salah satunya secara balance. Silang kolom ataupun baris yang sudah terpenuhi, bila baik kolom ataupun baris dipadati secara bertepatan cuma satu yang disilang. Sehabis membiasakan pengajuan serta permintaan buat seluruh kolom serta baris yang belum ditandai, melakukan kembali proses dengan membagikan skor paling tinggi bisa jadi di sel yang 
mempunyai bayaran elemen paling kecil selanjutnya ditandai yang belum. Prosedur ini dituntaskan kala pas satu baris ataupun kolom yang belum disilang.

Algoritma tata cara dengan biaya terkecil (Least Cost Method) buat menggapai pemecahan fisibel dini dari permasalahan transportasi merupakan selaku berikut:

1) Susun tabel dini yang berisikan tabel bayaran transportasi.

2) Cari sel yang mempunyai bayaran terkecil Cij pada tabel dini.

3) Pada Cij terkecil dialokasikan sebanyak bisa jadi tanpa melanggar batasan- batasannya. Mengisi $\mathrm{Xij}=\min (\mathrm{ai}, \mathrm{bj})$.- Jika bj\&lt; ai hingga $\mathrm{Xij}=$ bj kolom ke $\mathrm{j}$ tidak diperhitungkan lagi serta ai menurun sebesar bj.- Jika bj ai hingga $\mathrm{Xij}=$ ai baris ke i tidak diperhitungkan kembalii serta bj menurun sebesar ai.- Jika $b j=a i$ hingga $X i j=a i=b j$ baris ke $\mathrm{i}$ serta kolom ke $\mathrm{j}$ tidak dianggap lagi.

4) Cari sel yang mempunyai Cij terkecil, dilanjut dengan metode yang sama hingga seluruh persediaan habis serta permintaan terpenuhi.

Metode intuitif yaitu merupakan metode berbasis biaya yang digunakan untuk menemukan penyelesaian awal masalah transportasi. Metode Alokasikan secara intuitif berdasarkan ongksos terkecil. Dengan langkah perhitungannya adalah melewati:

1) Langkah 1: Lengkapi pengisian sel dengan mencari biaya minimum

2) Langkah 2: Isi sel hingga kapasitas maksimumnya (Jangan melewati kapasitas)

3) Langkah 3: Bila alokasi penuh sesuai dan kapasitas kemudian tambahkan Semua ongkos dikalikan dengan Sel yang terisi.

Keuntungan metode dengan biaya terkecil yaitu pengolahan yang digunakan dengan mencari ongkos yang paling terkecil atau minimum, sehingga akan memperoleh kesimpulan yang maksimum serta sesuai dalam menekan anggaran logistik yang akan dikeluarkan.

\section{c. Vogel Approximation}

Vogel Approximattion Method bisa disebut juga dengan VAM. Ini adalah teknik yang menemukan perselisihan harga terendah pada harga terendah lainnya, kemudian memberikannya di setiap kolom dan setiap baris, dan kemudian memilih harga tertinggi untuk menetapkan barang atau produk ke suku cadang dengan harga terendah. Metode ini lebih mudah digunakan karena tidak memerlukan jalur tertutup. Namun metode ini tidak menjamin penentuan biaya minimum atau minimum, sehingga lebih baik untuk menguji apakah nilai sel tabel non-basis $>0$ setelah produk dialokasikan. Hal ini untuk membuktikan bahwa biaya total yang sebenarnya adalah hasil yang terkecil. Sebelum mencari biaya terkecil, Anda harus menemukan biaya peluang setiap kolom dan baris dalam tabel, lalu memilih biaya terbesar dari kolom atau baris tersebut, lalu mengalokasikannya ke kapasitas dan permintaan terbesar yang mungkin di dalam sel. Berikut langkah-langkah dalam memecahkan masalah transshipment menggunakan metode VAM:

1) Langkah Pertama: Hitung penalti (peluang biaya) per kolom dan baris.

2) Langkah Kedua: Tentukan biaya penalti maksimum besar.

3) Langkah Tiga: Tetapkan biaya ke sel berdasarkan kondisi berikut: Biaya penalti tertinggi.

4) Langkah Empat: Tambahkan semua biaya Kalikan dengan sel yang terisi.

Tata cara Vogel Aproximation perhitungan tabel fesibel ini dengan tata cara ini lebih rumit dibanding 2 tata cara terdahulu ialah tata cara Bayaran Terendah serta tata cara Barat Laut. Hendak namun umumnya lebih mendekati penyelesaian optimalnya.

Algoritma Vogel Aproximation buat memastikan penyelesaian fisibel dini permasalahan transpotasi merupakan selaku barikut:

1) Di masing- masing baris serta kolom, buat taksiran selisih dua sel menggunakan anggaran terendah

2) Menetetapkan baris atau kolom hasil langkah pertama banyak yang diselisih. Bila ada lebih dari satu, seleksi secara acak.

3) Di baris atau kolom yang ditetapkan, isikan benda secara maksimum bisa jadi di sel dengan 
bayaran terendah. Hilangkan baris atau kolom yang di hapus sebab penetapan di taksiran selanjutnya. Bila baris serta kolom hilang bertepatan, tambah suatu variabel dummy.

4) Lakukan pengulangan langkah 1 - 3 sampai seluruh permintaan atau stok tidak ada sisa.

Bagi Siswanto (2006), Langkah- langkah tata cara VAM bisa diringkas selaku berikut:

1) Buatlah matrik yang menampilkan kebutuhan tiap- tiap sumber serta bayaran transportasi per unit.

2) Carilah selisih antara 2 bayaran terkecil di tiap- tiap kolom baris.

3) Pilih selisih terbanyak di antara selisih- selisih yang sudah dihitung pada langkah awal.

4) Sesuaikan penawaran serta permintaan buat menampilkan alokasi yang telah dicoba.

5) Hilangkan seluruh baris serta kolom dimana penawaran serta permintaan sudah dihabiskan.

6) Bila seluruh penawaran serta permintaan belum dipadati, kembali ke langkah 1, bila seluruh penawaran serta permintaan pemecahan dini diperoleh.

d. Modi

Setelah didapat pemecahan dini, berikutnya ialah memberikan kepastian untuk mengetahui pemecahan itu ialah paling baik (biaya paling minimum) atau belum. Dengan universal dapat diformulasikan untuk perhitungan nilai kolom dan baris :

$$
\mathrm{Cij}=\mathrm{Ri}+\mathrm{Kj}
$$

Keterangan:

$\mathrm{Ri}=$ nilai ditekankan kepada baris $\mathrm{i}$

$\mathrm{Kj}=$ nilai ditekankan kepada kolom $\mathrm{j}$

$\mathrm{Cij}$ = biaya pada sel $\mathrm{ij}$ (segi 4 di persinggungan baris I dan kolom $\mathrm{j}$ ).

Sehabis melakukan perhitungn seluruh nilai baris serta kolom, berikutnya ialah tata cara Modifikasi Distribusi (MODI) merupakan pengevaluasian masing- masing sel kosong untuk pemetaan, ialah melakukan perhitungan indeks untuk perbaikan. Untuk menghitung indeks revisi menggunakan rumus berikut :

Indeks Revisi $=\mathrm{Cij}-\mathrm{Ri}-\mathrm{Kj}$

Keterangan:

$\mathrm{Ri}=$ nilai yang ditekankan kepada baris $\mathrm{i}$

$\mathrm{Kj}=$ nilai yang ditekankan kepada kolom $\mathrm{j}$

$\mathrm{Cij}=$ biaya pada sel $\mathrm{ij}$ (segi empat di persinggungan baris I dan kolom $\mathrm{j}$ ).

Tata cara Modified Distribution (MODI), selaku berikut:

1) Merancang tabel model transportasi,

2) Hitung nilai indeks setiap kolom serta baris, rumus $\mathrm{Ri}+\mathrm{Kj}=\mathrm{Cij}$, $\mathrm{Ri}$ ialah skor indeks baris $\mathrm{i}, \mathrm{Kj}$ ialah skor indeks kolom $\mathrm{j}$, dan Cij ialah ongkos transportasi $\mathrm{j}$ dari sumber $\mathrm{i}$ ke destinasi j. Skor indeks tersebut harus diberikan atas sel sudah diisi atau dipakai. Menjadi alat untuk melakukan pencarian skor indeks, hinga skor baris awal (R1) dinyatakan nol, b). Gunakan rumus untuk mendapatkan nilai indeks semua kolom serta baris: $\mathrm{Ri}+\mathrm{Kj}=\mathrm{Cij}$,

3) Cari sel kosong atau sel tidak terisi,

4) Gunakan rumus Iij = Cij-Ri-Kj untuk menghitung nilai dalam sel kosong,

5) Jika nilai total sel kosong positif, berarti proses telah menciptakan biaya pengiriman minimum,

6) Jika masih ada nilai negatif berarti terdapat pembayaran dan tabungan sampai proses dicoba pada sel dengan angka negatif (jika ada beberapa nilai negatif, pilih nilai yang paling negatif)

7) Proses alokasi menggunakan metode terpadu dengan prosedur batu loncatan untuk dicoba. 
8) Mulai dari awal (langkah 1) dan ambil langkah untuk mengonfirmasi bahwa semua nilai sel kosong (Iij) tidak memiliki nilai negatif.

Algoritma dari Metode MODI (Modified Distribution) penulisannya ialah:

1) Memakai metode NW - Corner atau metode ongkos terkecil untuk melakukan penentuan tabel pertama yang fisibel.

2) Tambahkan variabel $\mathrm{Ri}$ serta $\mathrm{Kj}$ ke setiap baris dan setiap kolom.

3) Mencari nilai Ri dan Kj untuk setiap sel dasar dengan mengklasifikasikan salah satu nilai $\mathrm{Ri}$ atau $\mathrm{Kj}$ sebagai nol, dengan menggunakan rumus: $\mathrm{Ri}+\mathrm{Kj}=\mathrm{Cij}$.

4) Melakukan perhitungan semua nilai sel bukan basis dengan memakai rumus $\mathrm{Cij}-\mathrm{Ri}-\mathrm{Ki}$.

5) Tentukan sel yang akan masuk basis dengan memilih nilai sel non-dasar dengan nilai negatif terbesar. Kemudian buatlah desain jalur tertutup sehingga Anda dapat menentukan sel yang akan muncul dengan memilih sel total terkecil dari sel yang bertanda negatif.

6) Tabel optimum dapat terlampaui jika sel bukan basis semuanya mempunyai nilai $=0.7$. Apabila tabel belum optimal, kembali ke langkah 2 sehingga menemukan tabel optimum.

\section{Metode}

Di penelitian ini, pertama-tama yaitu dimulai dengan melakukan tahap pengumpulan data. Di tahap ini data yang didapat ialah data primer. Data primer di penelitian ini ialah data jarak dalam satuan kilometer dari beberapa gudang ke beberapa distributor serta ongkos pengiriman dari beberapa gudang ke beberapa distributor. Agar mendapatkan data primer tersebut, dilaksanakan dengan wawancara kepada pihak-pihak yang terkait yaitu Owner atau pemilik dari UKM Marcuy dan beberapa karyawan seperti kurir dan staff.

Sedangkan untuk data sekunder tim penulis dapatkan dari beberapa sumber yang relevan agar dapat mendukung penelitian ini. Setelah dari proses pengumpulan data, berikutnya melakukan pengolahan dan analisis data agar dapat menentukan rute dengan biaya pengiriman seminim mungkin pada proses distribusi produk UKM Marcuy. Metode penelitian pada penelitian ini menggunakan Metode Stepping Stone (Batu Loncat), Least Cost, Vogel Approximation Method (VAM) dan Modified Distribution (MODI). Keempat metode tersebut sangat bermanfaat dalam menentukan rute dengan biaya pengiriman seminim mungkin. Untuk gambaran tahap penelitiannya sebagai berikut :

a. Mengidentifikasi dan Merumuskan Masalah

Pada tahap tersebut peneliti melakukan penentuan topik penelitian dan pengangkatan permasalah yang akan digunakan menyesuaikan situasi yang terdapat di UKM Marcuy dengan melakukan identifikasi permasalahan apa saja yang menyambangi perusahaan. Setelah itu melakukan perumusan masalah tentang cara agar dapat meminimalkan biaya distribusi produk makaroni UKM Marcuy. Penelitian dilaksanakan di UKM Marcuy yang belokasi di Pasar Minggu, Jakarta Selatan. Penelitian memilki fokus di masalah distribusi produk makaroni

b. Menentukan Tujuan Penelitian

Di tahap ini menentukan langkah atau tujuan penelitian yang dilaksanakan berkaitan dengan masalah yang sudah ditimbulkan, ialah dapat diketahui biaya optimal mendistribusikan produk makaroni UKM Marcuy.

c. Menganalisis Data

Di langkah ini dilaksanakan analisis data sebagai suatu langkah menghitung dengan kuantitatif secara menggunakan rumus yang sudah dilakukan penentuan untuk menganalisis data yang menyesuaikan dengan permasalahan yang terjadi. Terdapat tahap-tahap untuk melakukan penyelesaiannya yaitu: (1) melakukan penentuan solusi fisibel pertama dan (2) melaksanakan pengujian optimalitas.

d. Melakukan Penentuan Solusi Fisibel Pertama

Solusi fisibel pertama ialah suatu solusi agar dapat melakukan pencarian untuk mengalokasikan pendistribusian barang yang bisa saja memiliki asal dari masing-maisng sumber ke masing-masing tujuan. Di penelitian kali ini solusi fisibel pertama yang digunakan dengan metode batu loncat (Stepping Stone), biaya terkecil (Least Cost Method), VAM (Vogel's Approximation Method, MODI (Modified Distribution). 


\section{Hasil dan pembahasan}

Pada penelitian yang dilakukan ini, data yang digunakan ialah jarak lokasi dari tempat pembuatan Makaroni Cihuy yang berada di daerah Setu Babakan dan Pasar Minggu ke 3 lokasi distributor yang berada di Depok, Pekayon dan Citeureup dengan anggaran pengiriman barang yang dikeluarkan UMKM Marcuy dalam jarak teretentu. Hal tersebut menjadi kendala, karena belum mengetahui anggaran pengiriman Marcuy dari gudang ke beberapa lokasi distributor. Dengan melakukan analisis dari data yang didapat berdasarkan kapasitas pembuatan sampai biaya pengantaran per km. UMKM Marcuy mengirimkan produk dari pabrik ke 3 lokasi distributor menggunakan sepeda motor dengan kapasitas 1-90 pcs untuk sekali pengiriman. Jumlah kapasitas produksi tiap pabrik pun berbeda sepeerti yang tertera pada tabel di bawah ini :

Tabel 1 Kapasitas Produksi

\begin{tabular}{|c|c|c|c|}
\hline No & Lokasi Gudang & \multicolumn{2}{|c|}{ Kapasitas Produksi } \\
\cline { 3 - 4 } & & Ukuran $90 \mathrm{~g}$ & Ukuran $133 \mathrm{~g}$ \\
\hline 1 & Setu Babakan & $10 \mathrm{pcs}$ & $40 \mathrm{pcs}$ \\
\hline 2 & Pasar Minggu & $20 \mathrm{pcs}$ & $50 \mathrm{pcs}$ \\
\hline
\end{tabular}

Dengan 2 lokasi pabrik tersebut, produk didistribusikan ke 3 lokasi distributor dengan lokasi yang berbeda menggunakan sepeda motor, yang pada tiap distributor memiliki permintaan ukuran yang berbeda-beda kepada pabrik :

Tabel 2. Kapasitas Permintaan

\begin{tabular}{|c|c|c|c|}
\hline No & Lokasi Distributor & \multicolumn{2}{|c|}{ Kapasitas Produksi } \\
\cline { 3 - 4 } & & Ukuran 90g & Ukuran 133g \\
\hline 1 & Depok & $5 \mathrm{pcs}$ & $20 \mathrm{pcs}$ \\
\hline 2 & Pekayon & $10 \mathrm{pcs}$ & $55 \mathrm{pcs}$ \\
\hline 3 & Citereup & $15 \mathrm{pcs}$ & $15 \mathrm{pcs}$ \\
\hline \multicolumn{2}{|c|}{ Jumlah } & $30 \mathrm{pcs}$ & $90 \mathrm{pcs}$ \\
\hline
\end{tabular}

Untuk pengiriman produk UMKM Marcuy mempunyai biaya yang berbeda, untuk biaya pengirimannya di setiap destinasi, dilakukan penyesuaian dengan jarak dan didapatkan yaitu tiap $1 \mathrm{Km}$ memiliki harga Rp 500. Pada tabel di bawah ini ialah data jarak dan biaya dari tempat asal (pabrik) sampai ke destinasi (3 lokasi distributor) sebagai berikut :

Tabel 3. Jarak Dari Pabrik ke Distributor

\begin{tabular}{|c|c|c|c|}
\hline DarilKe & Depok & Pekayon & Citereup \\
\hline Setu Babakan & $11 \mathrm{~km}$ & $10 \mathrm{~km}$ & $29 \mathrm{~km}$ \\
\hline Pasar Minggu & $19 \mathrm{~km}$ & $13 \mathrm{~km}$ & $31 \mathrm{~km}$ \\
\hline
\end{tabular}

Tabel 4. Biaya Per Kilometer

\begin{tabular}{|c|c|c|c|}
\hline DarilKe & Distributir 1 (Rp) & Distributir 2 (Rp) & Distributir 3 (Rp) \\
\hline Setu Babakan & $11 \mathrm{~km}$ & $10 \mathrm{~km}$ & $29 \mathrm{~km}$ \\
\hline Pasar Minggu & $19 \mathrm{~km}$ & $13 \mathrm{~km}$ & $31 \mathrm{~km}$ \\
\hline
\end{tabular}

Untuk mempermudah penghitungan, dilakukan penghilangkan 1 digit 0 pada data biaya per kilometer dalam tabel. Perihtungan dilaksanakan dengan beberapa metode, diantaranya ialah : 
1) Ukuran $90 \mathrm{~g}$

\begin{tabular}{|c|c|c|c|c|}
\hline $\mathrm{D}_{\text {Dari }}^{\mathrm{Ke}}$ & Depok (1) & Pekayon (2) & Citeureup (3) & Supply \\
\hline \multirow{2}{*}{ Setu Babakan (A) } & 55 & 50 & 145 & \multirow{2}{*}{10} \\
\hline & 5 & 5 & & \\
\hline \multirow{2}{*}{ Pasar Minggu (B) } & 95 & 65 & 155 & \multirow{2}{*}{20} \\
\hline & & 5 & 15 & \\
\hline Demand & 5 & 10 & 15 & 30 \\
\hline
\end{tabular}

Gambar 1. Perhitungan Stepping Stone

Solusi optimal untuk sel kosong ialah sebagai berikut:

$\mathrm{B} 1=\mathrm{B} 1-\mathrm{B} 2+\mathrm{A} 2-\mathrm{A} 1=95-65+50-55=25$

$\mathrm{A} 3=\mathrm{A} 3-\mathrm{A} 2+\mathrm{B} 2-\mathrm{B} 3=145-50+65-155=0$

Karena tidak ada nilai negatif (pengiritan biaya) dari hasil perhitungan, oleh karena itu proses eksekusi usai.

Diperoleh total biaya transportasi sebesar Rp. 31.750,-

2) Ukuran $133 \mathrm{~g}$

\begin{tabular}{|c|c|c|c|c|}
\hline $\mathrm{D}_{\text {Dari }}^{\mathrm{Ke}}$ & Depok (1) & Pekayon (2) & Citeureup (3) & Supply \\
\hline \multirow{2}{*}{ Setu Babakan (A) } & 55 & 50 & 145 & \multirow{2}{*}{40} \\
\hline & 20 & 20 & & \\
\hline \multirow{2}{*}{ Pasar Minggu (B) } & 95 & 65 & 155 & \multirow{2}{*}{50} \\
\hline & & 35 & 15 & \\
\hline Demand & 20 & 55 & 15 & 90 \\
\hline
\end{tabular}

Gambar 2. Perhitungan Stepping Stone

Solusi optimal untuk sel kosong adalah sebagai berikut:

$\mathrm{B} 1=\mathrm{B} 1-\mathrm{B} 2+\mathrm{A} 2-\mathrm{A} 1=95-65+50-55=25$

$\mathrm{A} 3=\mathrm{A} 3-\mathrm{A} 2+\mathrm{B} 2-\mathrm{B} 3=145-50+65-155=0$

Dikarenakan tidak terdapat nilai negatif (pengiritan biaya) dari hasil perhitungan, maka proses eksekusi usai. Diperoleh total biaya transportasi sebesar Rp. 67.000,-

\section{Metode Least Cost}

1) Ukuran $90 \mathrm{~g}$

Data pada tabel di bawah ini sebelumnya sudah dilakukan iterasi sebanyak dua kali pada bagian A1, B2 dan A3 untuk iterasi pertama dengan total biaya sebesar Rp. 33.000,- oleh karenanya, perlu dilakukan iterasi kedua seperti berikut ini :

\begin{tabular}{|c|c|c|c|c|}
\hline${ }_{\text {Dari }}{ }^{\mathrm{Ke}}$ & Depok (1) & Pekayon (2) & Citeureup (3) & Supply \\
\hline \multirow{2}{*}{ Setu Babakan (A) } & 55 & 50 & 145 & \multirow{2}{*}{10} \\
\hline & 5 & 5 & & \\
\hline \multirow{2}{*}{ Pasar Minggu (B) } & 95 & 65 & 155 & \multirow{2}{*}{20} \\
\hline & & 5 & 15 & \\
\hline Demand & 5 & 10 & 15 & 30 \\
\hline
\end{tabular}

Gambar 3. Perhitungan Least Cost

Solusi awal pada metode least cost adalah $\mathrm{A} 1=550, \mathrm{~B} 2=650, \mathrm{~A} 3=1450$, dan $\mathrm{B} 3=1500$.

Total Biaya $=5(550)+5(500)+15(1550)+5(650)$

$$
=31.750
$$


2) Ukuran $133 \mathrm{~g}$

Data pada tabel di bawah ini sudah dilakukan iterasi sebanyak dua kali pada bagian A1 dan A3 untuk iterasi pertama dengan total biaya sebesar Rp 62.250,- oleh karenanya, perlu dilakukan iterasi kedua seperti berikut ini :

\begin{tabular}{|c|c|c|c|c|}
\hline$\underset{\text { Dari }}{\mathrm{Ke}}$ & Depok (1) & Pekayon (2) & Citeureup (3) & Supply \\
\hline \multirow{2}{*}{ Setu Babakan (A) } & 55 & 50 & 145 & \multirow{2}{*}{40} \\
\hline & 20 & 20 & & \\
\hline \multirow{2}{*}{ Pasar Minggu (B) } & 95 & 65 & 155 & \multirow{2}{*}{50} \\
\hline & & 35 & 15 & \\
\hline Demand & 20 & 55 & 15 & 90 \\
\hline
\end{tabular}

Gambar 4. Perhitungan Least Cost

Solusi awal pada metode least cost adalah $\mathrm{A} 1=550, \mathrm{~B} 2=650, \mathrm{~A} 3=1450$, dan $\mathrm{B} 3=1500$.

Total Biaya $=20(550)+20(500)+15(1550)+35(650)$

$$
=67.000
$$

\section{Vogel's Approximation Method (VAM)}

1) Ukuran $90 \mathrm{~g}$

\begin{tabular}{|c|c|c|c|c|}
\hline Dari $\longrightarrow$ Ke & Depok (1) & Pekayon (2) & Citeureup (3) & Supply \\
\hline \multirow{2}{*}{ Setu Babakan (A) } & 55 & 50 & 145 & \multirow{2}{*}{10} \\
\hline & 5 & 5 & & \\
\hline \multirow{2}{*}{ Pasar Minggu (B) } & 95 & 65 & 155 & \multirow{2}{*}{20} \\
\hline & & 5 & 15 & \\
\hline & & 10 & 15 & 30 \\
\hline
\end{tabular}

Gambar 5. Perhitungan Vogel's Approximation Method

Total Biaya $=550(5)+500(5)+650(5)+1550(15)$

$$
=31.750 \text {,- }
$$

\begin{tabular}{|c|c|c|c|c|}
\hline $\mathrm{Dari}_{\text {Da }}^{\mathrm{Ke}}$ & Depok (1) & Pekayon (2) & Citeureup (3) & Supply \\
\hline \multirow{2}{*}{ Setu Babakan (A) } & 55 & 50 & 145 & \multirow{2}{*}{40} \\
\hline & 20 & 20 & & \\
\hline \multirow{2}{*}{ Pasar Minggu (B) } & 95 & 65 & 155 & \multirow{2}{*}{50} \\
\hline & & 35 & 15 & \\
\hline Demand & 20 & 55 & 15 & 90 \\
\hline
\end{tabular}

2) Ukuran $133 \mathrm{~g}$

Gambar 6. Perhitungan Vogel's Approximation Method

Total Biaya $=550(20)+500(20)+650(35)+1550(15)$

$$
=67.000,-
$$

\begin{tabular}{|c|c|c|c|c|c|}
\hline & & $\mathrm{V} 1=55$ & $\mathrm{~V} 2=50$ & $\mathrm{~V} 3=140$ & \\
\hline & 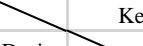 & Depok (1) & Pekayon (2) & Citeureup (3) & Supply \\
\hline \multirow[b]{2}{*}{$\mathrm{U} 1=0$} & \multirow{2}{*}{$\begin{array}{l}\text { Setu Babakan } \\
\text { (A) }\end{array}$} & 55 & 50 & 145 & 10 \\
\hline & & 5 & 5 & & 10 \\
\hline \multirow{3}{*}{$\begin{array}{c}\mathrm{U} 2= \\
15\end{array}$} & \multirow{2}{*}{$\begin{array}{l}\text { Pasar Minggu } \\
\text { (B) }\end{array}$} & 95 & 65 & 155 & 20 \\
\hline & & & 5 & 15 & \\
\hline & Demand & 5 & 10 & 15 & 30 \\
\hline
\end{tabular}

\section{MODI (Modified Distribution)}

1) Ukuran $90 \mathrm{~g}$

Gambar 7. Perhitungan Modified Distribution 
Menentukan nilai baris dan kolom dengan menghitung nilai-nilai ui dan vj pada setiap baris serta kolom menggunakan formula $u i+v j=c i j$

Tabel 5. Perhitungan Modified Distribution

\begin{tabular}{|c|c|c|c|}
\hline Misal $\mathrm{U} 1=$ & 0 & $\mathrm{U} 1=$ & 0 \\
\hline $\mathrm{U} 1+\mathrm{V} 1=$ & 55 & & \\
\hline $0+\mathrm{V} 1=$ & 55 & $\mathrm{~V} 1=$ & 55 \\
\hline $\mathrm{U} 1+\mathrm{V} 2=$ & 50 & & \\
\hline $0+\mathrm{V} 2=$ & 50 & $\mathrm{~V} 2=$ & 50 \\
\hline $\mathrm{U} 2+\mathrm{V} 2=$ & 65 & & \\
\hline $\mathrm{U} 2+50=$ & 65 & $\mathrm{U} 2=$ & 15 \\
\hline $\mathrm{U} 2+\mathrm{V} 3=$ & 155 & & \\
\hline $15+\mathrm{V} 3=$ & 155 & $\mathrm{~V} 3=$ & 140 \\
\hline
\end{tabular}

Menghitung indeks perbaikan kij pada nilai setiap sel yang kosong dengan cij-ui-vj=kij

Tabel 6. Perhitungan Modified Distribution

\begin{tabular}{|r|c|c|}
\hline $\mathrm{KA} 3=$ & $\mathrm{CA} 1-\mathrm{U} 1-\mathrm{V} 3$ & \\
\hline & $=145-0-140=$ & 5 \\
\hline $\mathrm{KB} 1=$ & $\mathrm{CB} 1-\mathrm{U} 2-\mathrm{V} 1$ & \\
\hline$=$ & $95-15-55=$ & 25 \\
\hline
\end{tabular}

Tidak terdapat nilai yang negatif, oleh karena itu tabel tidak perlu dilakukan perbaikan kembali, dapat disimpulkan bahwa perhitungan sudah optimal, yakni total biaya transportasi 550(5) +500(5) $+650(5)+1550(15)=31.750,-$

2) Ukuran $133 \mathrm{~g}$

\begin{tabular}{|c|c|c|c|c|c|}
\hline & & $\mathrm{V} 1=55$ & $\mathrm{~V} 2=50$ & $\mathrm{~V} 3=140$ & \\
\hline & $\mathrm{C}_{\text {Dari }}$ & Depok (1) & Pekayon (2) & Citeureup (3) & Supply \\
\hline \multirow[b]{2}{*}{$\mathrm{U} 1=0$} & \multirow{2}{*}{$\begin{array}{c}\text { Setu Babakan } \\
\text { (A) }\end{array}$} & 55 & 50 & 145 & \multirow{2}{*}{40} \\
\hline & & 20 & 20 & & \\
\hline \multirow{3}{*}{$\begin{array}{c}\mathrm{U} 2= \\
15\end{array}$} & \multirow{2}{*}{$\begin{array}{c}\text { Pasar Minggu } \\
\text { (B) }\end{array}$} & 95 & 65 & 155 & \multirow{2}{*}{50} \\
\hline & & & 35 & 15 & \\
\hline & Demand & 20 & 55 & 15 & 90 \\
\hline
\end{tabular}

Tabel 8. Perhitungan Modified Distribution

Menentukan nilai baris dan kolom dengan menghitung nilai-nilai ui dan vj pada setiap baris serta kolom menggunakan formula $u i+v j=c i j$

Tabel 7. Perhitungan Modified Distribution

\begin{tabular}{|c|c|c|c|}
\hline Misal U1= & 0 & $\mathrm{U} 1=$ & 0 \\
\hline $\mathrm{U} 1+\mathrm{V} 1=$ & 55 & & \\
\hline $0+\mathrm{V} 1=$ & 55 & $\mathrm{~V} 1=$ & 55 \\
\hline $\mathrm{U} 1+\mathrm{V} 2=$ & 50 & & \\
\hline $0+\mathrm{V} 2=$ & 50 & $\mathrm{~V} 2=$ & 50 \\
\hline $\mathrm{U} 2+\mathrm{V} 2=$ & 65 & & \\
\hline $\mathrm{U} 2+50=$ & 65 & $\mathrm{U} 2=$ & 15 \\
\hline $\mathrm{U} 2+\mathrm{V} 3=$ & 155 & & \\
\hline
\end{tabular}




\begin{tabular}{l|l|l|l|}
$15+\mathrm{V} 3=$ & 155 & $\mathrm{~V} 3=$ & 140
\end{tabular}

Menghitung indeks perbaikan kij pada nilai setiap sel yang kosong dengan cij-ui-vj=kij

Tabel 8. Perhitungan Modified Distribution

\begin{tabular}{|r|c|c|}
\hline $\mathrm{KA} 3=$ & $\mathrm{CA} 1-\mathrm{U} 1-\mathrm{V} 3$ & \\
\hline & $=145-0-140=$ & 5 \\
\hline $\mathrm{KB} 3=$ & $\mathrm{CB} 1-\mathrm{U} 2-\mathrm{V} 1$ & \\
\hline$=$ & $95-15-55=$ & 25 \\
\hline
\end{tabular}

Nilai indeks tidak terdapat yang negatif, maka tabel tersebut tidak ada perbaikan lagi, dapat disimpulkan bahwa hasil yang didapat telah optimal, yakni total biaya transportasi sejumlah $550(20)+500(20)+650(35)+1550(15)=67.000,-$

\section{Perbandingan Hasil Dari Keempat Metode}

Tabel 9. Perbandingan Hasil Dari Keempat Metode

\begin{tabular}{|c|c|c|c|}
\hline No & Metode & $\begin{array}{c}\text { Biaya Distribusi } \\
\text { (Ukuran 90 g) }\end{array}$ & $\begin{array}{c}\text { Biaya Distribusi } \\
\text { (Ukuran 133 g) }\end{array}$ \\
\hline 1 & Stepping Stone & Rp. 31.750 & Rp. 67.000 \\
\hline 2 & Least Cost & Rp. 31.750 & Rp. 67.000 \\
\hline 3 & $\begin{array}{c}\text { Vogel's } \\
\text { Approximation } \\
\text { Method (VAM) }\end{array}$ & Rp. 31.750 & Rp. 67.000 \\
\hline 4 & $\begin{array}{c}\text { Modified } \\
\text { Distribution } \\
\text { (MODI) }\end{array}$ & Rp. 31.750 & \\
\hline
\end{tabular}

Berdasarkan hasil analisis yang telah dilakukan dapat diketahui bahwa biaya distribusi optimal untuk keempat metode adalah sama baik untuk ukuran $90 \mathrm{~g}$ maupun $133 \mathrm{~g}$ berturut-turut adalah Rp. 31.750 dan Rp. 67.000. Namun demikian, analisis dengan menggunakan Metode Least Cost memerlukan waktu pengerjaan yang relatif lebih singkat dibandingkan ketiga metode lainnnya. Sehingga Metode Least Cost lebih direkomendasikan untuk menyelesaikan masalah optimasi biaya distribusi.

\section{Kesimpulan}

Berdasarkan hasil penelitian pada UKM Marcuy untuk mengetahui biaya yang dikeluarkan untuk proses pendistribusian produk dengan menggunakan metode Stepping Stone, Least Cost, Vogel Approximattion Method (VAM) dan Modified Distribution (MODI) diperoleh informasi bahwa biaya optimal adalah Rp. 31.750 untuk jenis produk kemasan 90 gr dan Rp. 67.000 untuk jenis produk kemasan 133 gr. Biaya ini lebih optimal dibandingkan dengan biaya distribusi yang selama ini dikeluarkan oleh UKM Markcuy. Meskipun keempat analisis menghasilkan nilai biaya distribusi yang sama, namun dalam segi efesiensi waktu, Metode Least Cost memerlukan waktu pengerjaan yang relatif lebih singkat dibandingan dengan ketiga metode yang lain dengan akurasi yang sama. Metode ini selanjutnya bisa menjadi referensi yang ditimbangkan oleh peneliti maupun pengusaha yang ingin mengoptimalkan biaya distribusi. Selain itu langkah pengerjaannya tidak sebanyak ketiga metode lain yang peneliti gunakan dan lebih mudah dalam melakukan perhitungan dan analisisnya. Dalam melakukan perhitungan dengan model transportasi untuk keempat metodeyang digunakan disarankan menggunakan aplikasi POM-QM sebagai acuan akurasi perhitungan. 


\section{Limitasi dan studi lanjutan}

Pada penelitian ini dilakukan pembatasan untuk produk macaroni UKM Marcu. Lebih lengkapnya, metode yang dipakai pada optimasi penentuan rute biaya pengiriman minimum ialah hanya metode Stepping Stone (Batu Loncat), Least Cost, Vogel Approximation Method (VAM) dan Modified Distribution (MODI).

\section{Referensi}

Aminudin, \& Simarmata, S. L. (2005). Prinsip-Prinsip Riset Operasi. Jakarta. Erlangga.

A. S. N. Srinivasan. (2017). An Improved Algorithm to Obtain Initial Basic Feasible Solution for the Transportation Problem. International Journal of Science and Research, 6(4), 1225-1229.

A. Wahyudi, H. Hidori, and P. Wibowo. (2020). Meminimumkan Biaya Distribusi Susu Bayi dengan Model Transhipment di PT Kamadjadja Logistics. Bulletin of Applied Industrial Engineering Theory, 2(1), 27-32.

E. Nugraha and R. M. Sari. (2019). Efektivitas Biaya Pengiriman pada Perusahaan Roti Dengan Menggunakan Metode Transportasi. Journal Competitive., 14, 21-26.

F. E. Putra, H. H. Purba, and I. A. Anggraeni, (2020). The Optimization of Distribution and Transportation Costs for Common Good Products. International Journal of Industrial Optimization., 1(2), 111.

Haliasih, N. P. E. W., \& Naryoto, P. (2021). Analisis Kelayakan Pengembangan Usaha Pasta Kangen Jupiter dan Mogot Jakarta Barat dengan Menggunakan Metode Capital Budgeting Tahun 20192023. Reviu Akuntansi, Manajemen, dan Bisnis, 1(1), 9-14.

Haobenu, S. E., Nyoko, A. E., Molidya, A., \& Fanggidae, R. E. (2021). Perencanaan Persediaan Bahan Baku pada UMK Tiga Bersaudara Kota Kupang dengan Metode Economic Order Quantity (EOQ). Reviu Akuntansi, Manajemen, dan Bisnis, 1(2), 61-75.

Herlawati. (2016). Optimasi Pendistribusian Barang Menggunakan Metode Stepping Stone dan Metode Modified Distribution ( MODI ). Information System for Educators and Professionals, 1(1), 103-113.

Render, B., \& Heizer, J. (2001). Prinsip-prinsip Manajemen Operasi.Jakarta. Salemba Empat.

H. O. Zulkarnaen and S. Sutopo. (2013). Analisis Strategi Pemasaran Pada Usaha Kecil Menengah (UKM) Makanan Ringan (Studi Penelitian UKM Snack Barokah di Solo. Diponegoro Journal Management, 2(3), 108-120.

H., S. Nugraha, dan M. Fauzi. (2020). Pengaplikasian Metode Stepping Stone Pada Sofware Lingo Untuk Mencari Optimasi Biaya (Studi Kasus PT Asm Mobil). Journal of Integrated System, $3(1), 49-58$.

I. W. Ardhyani. (2017). Mengoptimalkan Biaya Distribusi Pakan Ternak Dengan Menggunakan Metode Transportasi (Studi Kasus di PT. X Krian). Teknika Engineering and. Sains Journal, $1(2), 95$.

J. K. Appati, G. K. Gogovi, and G. O. Fosu. (2015). MATLAB Implementation of Vogel's Approximation and the Modified Distribution Methods. An Int. J. Adv. Comput. Technol., 4(1), $1449-1453$.

J. Nahar, E. Rusyaman, and S. D. V. E. Putri. (2018). Application of improved Vogel's approximation method in minimization of rice distribution costs of Perum BULOG. IOP Conference Series: Materials Science and Engineering, 332(1).

J. Reeb and S. Leavengood. (2002). Transportation Problem : A Special Case," Perform. Excell. Woord Prod. Ind. Oper. Res., 1-36.

K. Erwansyah, N. B. Nugroho, and H. Jaya. (2017). Penerapan Metode Vogel Aproximation Untuk Efisiensi Biaya Pengiriman Barang Pada Tiki ( Titipan Kilat ). Saintikom, 16(3), 323.

Kurniasih, D dan Elizabeth (2021). Pengaruh Kualitas Pelayanan, Citra Merek dan Getok Tular terhadap Keputusan Pembelian Jasa. Reviu Akuntansi, Manajemen, dan Bisnis, 1(1), 1-8.

M. Ary and D. Syarifuddin (2011). Between Northw est-Corner Method And Stepping-, 35-44.

M. A. Septiana, R. Hidayattulloh, J. Machmudin, and N. F. Anggraeni. (2020). Optimasi Biaya Pengiriman Kelapa Menggunakan Model. J. Rekayasa Sist. Ind., 5(2), 111-115,

M.Mujiono and S. Sujianto. (2019). Optimalisasi Biaya Transportasi Di Industri Manufaktur. Pros. SENIATI, 1(2), 157. 
Miro, F. (2005). Perencanaan Transportasi untuk Mahasiswa, Perencana dan Praktisi.

M. Nadapdap. (2020). North West Corner and the Stepping Stone Method Solving Transshipment Problems. International Journal of Basic and Applied Science, 9(2), 38-44.

N. Iswanti, N. A. Hasibuan, and M. Mesran. (2016). Aplikasi Transportasi Pengiriman Barang Menggunakan Metode Least Cost Dan Modified Distribution Pada CV. Nihta Cargo Express. JURIKOM (Jurnal Riset Komputer), 3(6), 106-110.

N. Sen, T. Som, and B. Sinha. (2010). A study of Transportation Problem for an Essential Item of Southern Part of North Eastern Region of India as an OR Model and Use of Object Oriented Programming. Int. J. Comput. Sci. Netw. Secur., 10(4), 78-86.

Pranati, N. M. A., Jaya, A. I., \& Sahari, A. (2018). Optimalisasi Biaya Transportasi Pendistribusian Keramik Menggunakan Model Transportasi Metode Stepping Stone (studi kasus: PT. Indah bangunan). Jurnal Ilmiah Matematika dan Terapan, 15(1), 48-57.

Primiana, I. (2009). Moving the Real Sector of SMEs and Industry. Bandung: Alfabeta.

Q. W. R. M. M. Brain. (2012). RP For RW Only. Int. J. Comput. Integr. Manuf., 29, 792-803.

Siswanto. (2006). Pengantar Manajemen. Jakarta : BumiAksara.

Taha, H. A. (1996). Riset Operasi: suatu pengantar. Jakarta: Binarupa Aksara.

Widyawati, S., \& Faeni, R. P. (2021). Pengaruh Marketing Online, Kualitas Pelayanan dan Harga terhadap Kepuasan Konsumen Hotel Borobudur. Reviu Akuntansi, Manajemen, dan Bisnis, 1(1), 15-19.

Z. A. M. S. Juman, M. A. Hoque, and M. I. Buhari. (2013). Sensitivity analysis and an implementation of the Wellknown Vogel's approximation method for solving unbalanced transportation problem. Malaysian Journal of Science, 32(1), 66-72. 